\title{
BMJ Open Examining influences on antibiotic prescribing by nurse and pharmacist prescribers: a qualitative study using the Theoretical Domains Framework and COM-B
}

\author{
Molly Courtenay, ${ }^{1}$ Samantha Rowbotham, ${ }^{2}$ Rosemary Lim, ${ }^{\oplus}$ Sarah Peters, ${ }^{4}$ \\ Kathryn Yates, ${ }^{5}$ Angel Chater ${ }^{6}$
}

To cite: Courtenay M, Rowbotham S, Lim R, et al. Examining influences on antibiotic prescribing by nurse and pharmacist prescribers: a qualitative study using the Theoretical Domains Framework and COM-B. BMJ Open 2019;9:e029177. doi:10.1136/ bmjopen-2019-029177

- Prepublication history and additional material for this paper are available online. To view please visit the journal (http:// dx.doi.org/10.1136/bmjopen2019-029177).

Received 16 January 2019

Revised 1 April 2019

Accepted 29 May 2019
Check for updates

(C) Author(s) (or their employer(s)) 2019. Re-use permitted under CC BY-NC. No commercial re-use. See rights and permissions. Published by BMJ.

For numbered affiliations see end of article.

Correspondence to Professor Molly Courtenay; courtenaym@cardiff.ac.uk

\section{ABSTRACT}

Objectives Respiratory tract infections are frequently managed by nurse and pharmacist prescribers, and these prescribers are responsible for $8 \%$ of all primary care antibiotic prescriptions. Few studies have explored antibiotic prescribing among these prescribers, and interventions to target their antibiotic prescribing behaviour do not exist. Research objectives were to: (1) use the Theoretical Domains Framework to identify the factors that influence nurse and pharmacist prescriber management of respiratory tract infections and (2) identify the behaviour change techniques (BCTs) that can be used as the basis for the development of a theoretically informed intervention to support appropriate prescribing behaviour.

Design Qualitative design comprising semistructured interviews, using the Theoretical Domains Framework and Capability, Opportunity and Motivation for Behaviour.

Setting Primary care.

Participants Twenty one prescribers (4 pharmacists and 17 nurses).

Results A range of factors across 12 domains of the TDF were found to influence prescriber behaviour, and 40 BCTs were identified as supporting appropriate prescribing. For example, patient expectations (social influence) was identified as a factor influencing prescribing decisions, and a number of BCTs (problem solving, goal setting and information about health consequences) were identified as supporting prescribers in managing these expectations.

Conclusion With increasing numbers of nurse and pharmacist prescribers managing infections in primary care, these findings will inform theoretically grounded interventions to support appropriate prescribing behaviour by these groups.

\section{INTRODUCTION}

Multidrug-resistant infections are one of the greatest threats to human health, ${ }^{1}$ responsible for an estimated 25000 deaths and $€ 1.5$ billion in extra healthcare costs every year in the European Union alone. ${ }^{2}$ Between 2000 and 2010, the global human consumption of
Strengths and limitations of this study

- Using an established framework to explore the theoretical mechanisms of action and mechanisms of change to understand the antibiotic prescribing behaviour of nurse and pharmacist prescribers is a key strength.

- Although participants were a national sample, few were pharmacists and so our findings may not present an accurate picture of this population; however, this sample reflects UK primary care where most prescribers are nurses.

- Although data saturation was achieved, participants were an opportunistic sample and may have been more motivated towards appropriate antibiotic prescribing.

antibiotics increased by $36 \%{ }^{3}$ The inappropriate use of antimicrobials in humans, is a leading driver for the increase in antimicrobial resistance $(\mathrm{AMR})^{4}$; however, resistance is reversible, ${ }^{5}$ and strategies that support appropriate antibiotic use are crucial. ${ }^{6}$

Most antibiotics are prescribed in primary care for respiratory tract infections (RTIs) ${ }^{7-9}$; however, most RTIs spontaneously resolve without an antibiotic. Conserving antibiotic sensitivity through the management of RTIs without recourse to antibiotics is a global priority, ${ }^{5} 71011$ and the antibiotic prescribing behaviour of healthcare professionals is a key target for intervention.

Existing research has focused on understanding how general practitioners (GPs) make prescribing decisions for patients with acute RTIs. Key influences include perceptions of patient expectations, ${ }^{12}$ patient pressure, ${ }^{13}$ diagnostic uncertainty, ${ }^{14}$ factors imposed by healthcare systems and clinician characteristics. ${ }^{15}$ Systematic reviews ${ }^{16}{ }^{17}$ have 
identified that effective interventions are those that target the broader patient population, are complex and multifaceted in addressing barriers to change in specific healthcare settings. Multifaceted interventions that promote shared decision making ${ }^{18}$ have also had promising results.

In the UK, around 30000 nurses and 4000 pharmacists have the same independent prescribing capability as doctors. ${ }^{19}$ The numbers of these 'non-medical prescribers (NMPs)' is steadily increasing ${ }^{19}$ to fulfil the workforce needs of the National Health Service (NHS) ${ }^{20-22}$ These prescribers frequently manage patients with RTIs and are responsible for $8 \%$ of all primary care antibiotic prescriptions ${ }^{15}$; however, few studies have explored their antibiotic prescribing practices. Like GPs, diagnostic ambiguity and patient expectations can influence decision making. ${ }^{23}$ Furthermore, NMPs perceive themselves to be open to scrutiny by medical prescribers and are conscious of keeping to clinical guidelines. ${ }^{23}$ Although NMPs have developed strategies for managing RTI consultations, there is scope for improvement. ${ }^{24}$

Interventions must be tailored to the population and context in which the target behaviours are delivered. ${ }^{25}{ }^{26}$ Although interventions exist to support the antimicrobial stewardship (AMS) activities in which NMPs are involved ${ }^{27}$ no interventions exist to target their antibiotic prescribing behaviour.

Growing evidence supports the use of theory to identify barriers and facilitators to changing practitioner behaviour. ${ }^{17} 28$ One such approach is the Behaviour Change Wheel (BCW) ${ }^{26}$ The original BCW encompasses three layers that should be considered when supporting behaviour change: (1) the determinants of behaviour (Capability, Opportunity and Motivation for Behaviour (COM)-B); (2) intervention functions with which to intervene with these determinants; and (3) policy categories to support change on a more structural level. At the hub of the BCW, the COM-B model aims to facilitate a behavioural diagnosis by understanding the determinants of behaviour, highlighting an individual's capability, both physical (such as skills) and psychological (such as knowledge); their opportunity, both social (norms of practice) and physical (time/space); and motivation, both reflective (influenced by beliefs such as confidence and intention) and automatic (influenced by emotion or habit). This model is helpful when developing an intervention, as it can be easily mapped to an Intervention function (ie, education, training and enablement) using the table in Michie et $a .^{29}$ The Theoretical Domains Framework $(\mathrm{TDF})^{30}$ unpacks the COM-B further, as it separates psychosocial drivers of behaviour into 14 domains covering a spectrum of theoretical determinants (knowledge, memory, skills and identity). This helps separate potential ambiguity when attempting to contextualise the determinants of COM-B, that is, a psychological capability barrier could be both a lack of knowledge or poor memory, each of which would require a different Intervention function, for example, education to increase knowledge or enablement to enhance memory, and in turn different behaviour change techniques (BCTs), for example, giving information to increase knowledge, using prompts and cues to enhance memory. As this science has developed, the TDF has been conceptualised as an additional layer to the BCW after the COM-B ${ }^{28} 31$ and COM-B has been mapped to the $\mathrm{TDF}^{26}$ and a selection of BCTs from the BCT Taxonomy Version $1^{32}$ that can be selected as intervention components to change behaviour. ${ }^{28}$

However, there is another way to identify and code BCTs related to the facilitators of behaviour that lacks empirical evidence. Qualitative exploration allows for both an in-depth COM-B/TDF behavioural diagnosis and the identification of naturally occurring BCTs used by the target population when the target behaviour is facilitated.

\section{Objectives}

- To use a theoretical framework to identify the factors that influence management of RTIs.

- To identify BCTs that can be used as the basis for the development of a theoretically informed intervention to support appropriate prescribing behaviour.

\section{METHODS}

\section{Design}

A qualitative approach using semistructured interviews.

\section{Recruitment of participants}

NMPs work in a variety of roles in primary care across a range of settings. ${ }^{33} 34$ The uptake of prescribing among these healthcare professionals is inconsistent across organisations $^{33} 34$ and not all of these professionals manage RTIs. Therefore, an opportunistic sample of primary care nurse and pharmacist-independent prescribers, responsible for managing patients with RTIs, were recruited nationally. Recruitment occurred through the Royal College of Nursing General Practice (RCNGP) Nurse Forum (approximately 6000 members), the Royal Pharmaceutical Society (RPS) Pharmacist Prescribing Discussion Group (783 members), Prescribing and Medicines Management Discussion Group (520 members), Pharmacists working in GP practices Discussion Group (531 members) and the Queens Nurse Network (1200 members).

Messages were placed on the RCNGP Nurse Forum and the three RPS Pharmacist Prescribing Discussion Groups, describing the study and inviting eligible participants to contact the researchers. Details of the study were emailed to members of the Queens Nurse Network by the director of programmes. It is not known how many nurses and pharmacists across the forums, discussion groups and network are qualified prescribers or how many manage RTIs. Thirty-one prescribers expressed an interest to take part, and 21 (4 pharmacists and 17 nurses) consented to participate.

\section{Materials}

An interview schedule was developed based on the TDF (see table 1). This was a guide, and the interviewer was responsive to answers from interviewees. The TDF, as opposed to 
Table 1 Interview schedule and questions under each theoretical domain

\begin{tabular}{|c|c|}
\hline Theoretical domain & Interview questions \\
\hline Knowledge & $\begin{array}{l}\text { What do you know about the use of antibiotics for self-limiting RTIs? } \\
\text { What knowledge do you draw on when managing patients with RTIs? }\end{array}$ \\
\hline Social/professional role & $\begin{array}{l}\text { What do you think is your role in reducing antibiotic use and antimicrobial resistance? } \\
\text { To what extent do you see this as part of your job? } \\
\text { What is the role of other practitioners in reducing antibiotic use and antimicrobial resistance? }\end{array}$ \\
\hline Beliefs about capabilities & $\begin{array}{l}\text { How confident do you feel that you are able to manage RTI consultations? } \\
\text { How confident do you feel in making decisions about whether to prescribe antibiotics? } \\
\text { What if you are unsure about a diagnosis? }\end{array}$ \\
\hline Optimism & $\begin{array}{l}\text { How confident are you that your consultations with patients with RTIs will have a positive outcome? } \\
\text { How is this affected by whether an antibiotic is prescribed? }\end{array}$ \\
\hline Intentions & What motivates you to prescribe or not? \\
\hline $\begin{array}{l}\text { Memory/attention/decision } \\
\text { process }\end{array}$ & $\begin{array}{l}\text { How do you decide whether or not to prescribe an antibiotic to someone presenting with RTI? } \\
\text { What processes do you usually follow when managing patients with RTIs? }\end{array}$ \\
\hline $\begin{array}{l}\text { Environmental context and } \\
\text { resources }\end{array}$ & $\begin{array}{l}\text { What factors support or hinder you to manage these consultations (eg, practice setting, community } \\
\text { factors and available resources)? } \\
\text { How do systems in place support you to prescribe appropriately? }\end{array}$ \\
\hline Social influences & $\begin{array}{l}\text { How do patients influence the way you manage RTI consultations and whether you prescribe antibiotics? } \\
\text { How do the people you work with influence your management of RTIs and your decisions around whether } \\
\text { to prescribe antibiotics? }\end{array}$ \\
\hline
\end{tabular}

$\mathrm{RTI}$, respiratory tract infection.

the simpler COM-B, allowed a more detailed investigation of behavioural determinants.

\section{Procedure}

Prescribers who had expressed interest in the study were emailed a participant information sheet and a consent form. They were able to ask any questions prior to providing consent before their interview. Semistructured telephone interviews were conducted by an experienced qualitative researcher (TC) and were audio-recorded and transcribed verbatim. Data collection was between June and July 2017. Mean interview time was $45 \mathrm{~min}$ (range 25-65 min).

\section{Data analysis}

Taking an inductive approach and drawing from thematic analysis, ${ }^{35}$ two researchers (TC/MC) independently coded the transcripts using NVivo data management software. Initial codes and emerging themes were reviewed with a third qualitative researcher (SR). Saturation was achieved (later interview data were categorised within the coding frame with no new codes). In line with healthcare research that has used the TDF and COM-B in interviews with practitioners in general practice, ${ }^{36}$ the third researcher then deductively mapped codes to the appropriate 'domains' within the TDF with ongoing discussion with MC. All codes were mapped onto at least one domain. A further qualitative researcher with expertise in the BCW (AC), then checked and agreed initial codes and their relevance to each TDF domain. Using the Behaviour Change Techniques Taxonomy (BCTT) $\mathrm{v} 1,{ }^{32}$ quotes were then coded by AC for the BCTs that the population had described when discussing what influences their behaviour and subsequently checked by SR and MC. A member checking exercise was considered but deemed unnecessary as the approach was deductive and required coding according to the TDF and BCT taxonomy.

\section{Patient and public involvement}

Patients were not involved in the development of the research question, outcome measures, design of the study or, recruitment to, and conduct of, the study. 
Table 2 Demographic details

\begin{tabular}{|c|c|c|c|c|c|c|}
\hline Interviewee & Role & $\begin{array}{l}\text { Time } \\
\text { qualified in } \\
\text { current role }\end{array}$ & $\begin{array}{l}\text { Time } \\
\text { qualified as } \\
\text { a prescriber }\end{array}$ & Clinical setting & $\begin{array}{l}\text { No. of RTIs consultations a } \\
\text { week }\end{array}$ & $\begin{array}{l}\text { Length of } \\
\text { appointment } \\
\text { (min) }\end{array}$ \\
\hline 1 & Nurse practitioner & 11 & 7 & $\begin{array}{l}\text { Out-of-hours walk-in } \\
\text { service. }\end{array}$ & $\begin{array}{l}25 \text { in summer months but } \\
\text { many more in winter. }\end{array}$ & 15 \\
\hline 2 & $\begin{array}{l}\text { Advanced nurse } \\
\text { practitioner }\end{array}$ & 5 & 5 & General practice. & $\begin{array}{l}20 \text { summer months and } 40 \\
\text { winter months. }\end{array}$ & 15 \\
\hline 3 & $\begin{array}{l}\text { Advanced } \\
\text { nurse practitioner }\end{array}$ & 14 & 8 & General practice. & 75 in the winter 30 in summer. & 15 \\
\hline 4 & $\begin{array}{l}\text { Advanced nurse } \\
\text { practitioner }\end{array}$ & 2.5 & 17 & General practice. & 25 & 10 \\
\hline 5 & $\begin{array}{l}\text { Advanced nurse } \\
\text { practitioner }\end{array}$ & 24 & 14 & $\begin{array}{l}\text { Intermediate care (keep } \\
\text { patients out of hospital). }\end{array}$ & $\begin{array}{l}25 \text { in the summer more in } \\
\text { winter. }\end{array}$ & $30-45$ \\
\hline 6 & $\begin{array}{l}\text { Lead nurse in a general } \\
\text { practice walk-in centre }\end{array}$ & 7 & 7 & Walk-in centre. & 30 & 15 \\
\hline 9 & $\begin{array}{l}\text { Advanced nurse } \\
\text { practitioner }\end{array}$ & 3 & 1 & General practice. & 30 & 15 \\
\hline 10 & Nurse & 32 & 3 & $\begin{array}{l}\text { Intermediate care (keep } \\
\text { patients out of hospital). }\end{array}$ & (missing data). & $30-120$ \\
\hline 11 & $\begin{array}{l}\text { Advanced nurse } \\
\text { practitioner }\end{array}$ & 6 & 7 & $\begin{array}{l}\text { General practice and out-of- } \\
\text { hours service. }\end{array}$ & 50 & 15 \\
\hline 12 & $\begin{array}{l}\text { Advanced nurse } \\
\text { practitioner }\end{array}$ & 4 & 6 & General practice. & 40 & 15 \\
\hline 13 & $\begin{array}{l}\text { Advanced nurse } \\
\text { practitioner }\end{array}$ & 11 & 11 & (missing data) & Several a day. & 2 hours \\
\hline 14 & Clinical pharmacist & 3 & 10 & General practice. & $16-20$ & 15 \\
\hline 20 & Pharmacist & 11 & 6 & General practice. & 25 & 15 \\
\hline 21 & Pharmacist & 24 & 6 & General practice. & Varied & 20 \\
\hline
\end{tabular}

\section{RESULTS}

\section{Participants}

Twenty-one prescribers (4 pharmacists and 17 nurses), with between 1 year and 17 years' prescribing experience (mean 8.5 years, SD 3.7) and between 2.5-32 years' experience in their current role (mean 11 years, SD 8.5) took part in interviews. Most worked in general practice, had 15 min consultations and reported seeing around 25 patients a week with RTIs (see table 2).

\section{Factors influencing the management of RTIs}

Twenty-six codes were inductively assigned to the data from the interview transcripts. Codes were then mapped to the TDF domains, whereby 12 domains were identified as factors that influence appropriate antibiotic prescribing. TDF domains were then mapped onto the COM-B model to enable future intervention design (see online supplementary table 1 ).
The section below describes how data align within the TDF domains. Interview quotes are followed by letters and numbers in brackets that indicate the interviewee number ( $\mathrm{I}=$ interviewee, $\mathrm{n}=$ nurse, $\mathrm{P}=$ pharmacist $)$.

\section{Knowledge (Psychological capability)}

Influences on antibiotic prescribing included knowledge of current prescribing guidelines and AMS practices (with training mechanisms in place to facilitate this) and knowledge of AMR and its consequences at an individual and a population level. Awareness of own prescribing rate compared with other prescribers and national prescribing levels was another important influence.

... [W] e have a training session, like an audit with the local CCG [clinical commissioning group] team, in relation to our practices antibiotic prescribing and comparing it to the area in the north west... so that 
kind of helped influence and perhaps reduced my antibiotic prescribing. (I13N)

\section{Memory, attention and decision processes (psychological} capability)

Treatment decisions were made by weighing up information from guidelines, patient pre-existing conditions, and illnesses present within the local community, and a full examination and point of care testing if appropriate.

If we have decided that they do have an acute bacterial (infection) that would benefit from antimicrobial treatments, I would use the HPA guidelines, un-amended. So we follow the guidelines that are the national ones, and depending on the patient's situation because of the allergies, co-existing conditions, previous treatment perhaps, knowledge of locally circulating bugs, and I would choose according to that. $(\mathrm{I} 13 \mathrm{~N})$

\section{Behavioural regulation (psychological capability)}

Awareness of antibiotic prescribing rate in relation to colleagues and ability to self-regulate behaviour influenced prescribing practice as described above. Self-auditing of prescribing practice was also viewed as valuable.

I am happy about that, because that is all about auditing your own practice and doing things like that yes. I mean I do go through periods where I audit people that I see, what's happened, did they come back, did they get better, did they get worse, and that also kind of reassures you as well that you are either doing the right or the wrong thing...(I3N)

\section{Skills (physical capability)}

A range of skills were described as those required to manage the consultation, including physical examination and communication skills.

Typically, the clinical examination would start with sats, move on to lymph's, then we would go to throat, we go to ear examination if it was indicated, then potentially shirt off, and we would do respiratory signs front and back oscultation, percussion... shirt back on, summary of assessments, patient's point of view, consider treatments or safety netting, whether it be immediate treatment or whether it be standby treatments or it would be no you have got a viral infection here, so we go through the signs and what to look out for. And then .... make sure that they knew what to do if things were to go badly, and when to seek review. $(\mathrm{I} 17 \mathrm{~N})$

Competence in these skills, acquired through practice, was viewed as important

... [Y] ou have to be competent, not only with your history taking... But, examination skills; you have to be able to examine... The patient; you have to be able to relate those findings... to the patient in a language that they can understand. (I15N)

\section{Social/professional role and identity (reflective motivation)}

Elements of the NMP role (ie, time to talk to patients, being up to date with guidelines and the stringency of prescribing rules) supported appropriate antibiotic prescribing. Participants saw themselves as personally and professionally responsible for appropriate prescribing. Several highlighted their role as antibiotic guardians (ie, taken a pledge to prescribe responsibly) to manage patient expectation.

... [S] o I've got that responsibility to the health service and to society, and that partly comes with the privilege of being a prescriber... I think this is definitely part of my role. (I17N)

\section{Beliefs about capabilities (reflective motivation)}

Newly qualified prescribers reported how a lack of confidence meant advice from more senior colleagues could negatively influence prescribing decisions, while others indicated they were confident, recognising the limits of their role.

... [T] here is one drug that you used to prescribe for chest infections and it was always for 7 days and the guidelines now are actually for 5 days, and now I always check my guide ... and now I am more confident to say no actually it should only be five but when I very first started prescribing I found that really difficult ... because I felt maybe I should be prescribing longer than it says on the guide, because more experienced people are telling me that, so I think when you are a newly qualified prescriber, the more experienced people can have a strong influence over you and it is not always right. (I10N)

\section{Beliefs about consequences (reflective motivation)}

Prescribers described 'managing risk' by being cautious about withholding antibiotics when managing patients at risk of developing complications, for example, children, elderly patients or those with pre-existing conditions, alongside those where there was diagnostic uncertainty due to a language barrier. In these cases, they were more likely to prescribe antibiotics.

I may treat someone who is very frail, but I wouldn't treat someone who is well... simply because the consequences of not treating would be more serious, with the risk of hospitalisation. So I am talking about a threshold prescribing, and I think I do adjust that threshold according to the individual... based on their risk. (I10N)

The consequences of antibiotic use, at an individual and population levels, influenced prescribing decisions. Prescribers believed that prescribing antibiotics 
unnecessarily reinforced patients' beliefs they were the appropriate treatment and influenced future expectations.

Some GP's will just write a prescription for 7 days with $250 \mathrm{mg}$ of amoxicillin, three times a day. And it's a homeopathic dose it's a pat on the head and a piece of green paper, and the patient comes away from that consultation happy, they have got their antibiotics, they won't get better because of the antibiotics, they will get better because it is self-limiting, viral RTI. But what that health care professional is doing, is perpetuating the expectation of I am unwell, I will get antibiotics I will get better. The hard thing you have to do as a prescriber is to turn around and say you don't need antibiotics at this time. (I11N)

Fear of a complaint as a consequence of not prescribing sometimes influenced prescribing decisions and some reported prescribing antibiotics in some cases because patients would just reconsult if they were not given them.

\section{Goals (automatic motivation)}

Prescribing at an appropriate rate was a key goal for some prescribers. Audit and benchmarking practices were motivators to reduce prescribing, introducing competition to be the prescriber with the lowest rate.

I am someone with lower antibiotic prescribing rates however, I only work part time. I wouldn't want my data to be high as this would look really bad amongst colleagues. (I16N)

\section{Reinforcement (automatic motivation)}

Rewards were used by management teams to reinforce appropriate prescribing behaviour for example in the prescribers use of certain antibiotics.

This year we have looked at the use of quinolones, ketasporines and Co-amoxiclav... influenced by the national agenda but also our local medicines management team at the CCG, they push that agenda as one of their priorities for the year and resource it through the prescribing incentive scheme. So inevitably there were rewards available to practices and practitioners, so that will influence my prescribing for sure. (I21P)

Auditing the prescription of antibiotics by management teams and benchmarking against peers had a positive influence on prescribing practice and was viewed as necessary.

So over in Bath and Somerset, that is what they (medicines management team) has been doing, so if you are over prescribing, against your peers, you are identified and you are invited to come down for a training day. It is a little bit heavy handed, but we are heading towards a very scary place and I think we need to be quite bold with our interventions. (I2N)

\section{Emotion (automatic motivation)}

Antibiotics were sometimes prescribed to manage patients when explanations for a no-antibiotic decision had failed. Empathy for unwell patients could also make a no prescribing decision difficult. The time of day, day of the week, feeling stressed and tired also influenced prescribing, prescribers, in these instances, being less conservative in their use of antibiotics.

... [T] owards the end of the day, I am a little bit more lenient, because you are tired and a bit stressed and you want to go home, and sometimes it can be an easy fix. I try not to, but sometimes, whether at the beginning of the day you weren't quite sure, you would rationalise it a bit more and explain it a bit more, whereas you might at the end of the day, you might sort of lean to like well I am not quite sure, ok just take them. (I12N)

\section{Environmental context and resources (physical opportunity)}

Participants described how they used an array of accessible resources, including tailored and locally relevant information, local and national guidelines, point-of-care testing, decision support tools and information about patients (including comorbidities, previous antibiotic use and frequency of return visits), to inform treatment decisions and to communicate decisions to their patients. Time pressures was reported by some prescribers to impact negatively on prescribing. Many acknowledged that having longer appointment times (15 min) than GPs, facilitated patient education and discussions about treatment decisions.

... so the GPs get $10 \mathrm{~min}$... myself and some of the Nurse Practitioners that I work with ... in our practice have $15 \ldots$ after a few years of experience, we kind of can do a respiratory tract infection consultation in 10 min... you can do it, so you still have that extra sort of like two to three, $4 \mathrm{~min} .$. . Which we can spend on educating the patient. (I7P)

Time and resources to follow-up patients, encouraging patients to return if symptoms did not improve and the ability to allow patients to contact them quickly were highlighted as important by some prescribers. Patient features, such as age, influenced the ease with which it was possible to manage RTIs without antibiotics, with technological literacy cited as being helpful here. Language barriers were also reported to be a problem while maintaining appropriate prescribing.

\section{Social influences (social opportunity)}

A range of strategies, including reassurance, education (including information on symptoms, length of time to get better, self-management and red flags) and active patient engagement in decision making were used to manage patients' expectations. Patients pressure for an antibiotic was described as a key challenge and strategies to manage this included delayed prescribing, patient education and 
consistency in antibiotic use. Public awareness campaigns and environmental prompts were also helpful. Good rapport and a trusting relationship were important when communicating a 'no prescribing' decision. Most prescribers discussed the role of other prescribers in influencing their prescribing decisions, including the role of social and collaborative networks. Collaborative working helped avoid situations whereby patients try to obtain an antibiotic from a different prescriber and reassured prescribers that they were consistent in their decision making. However, such working occasionally led to problems, especially when disputes about the appropriateness of antibiotics arose and the other prescriber was a clinician.

People (another prescriber) will say, just give them another one (different type of antibiotic), and I will think that's not really what I am asking you, I just wanted to discuss it and see if we can do something else, because I am not really sure if it is going to do anything if I do take you know (different type of antibiotic)... But then you are arguing with another clinician and maybe that is a doctor versus another nurse practitioner, so there is a slightly different playing field there. So yes those are some of the things (that influence prescribing). (I3N)

\section{Identification of BCTs}

Forty naturally occurring BCTs (see online supplementary table 1) were identified as used by nurse and pharmacist prescribers when the target behaviour (ie, appropriate antibiotic prescribing) is facilitated. Two or more of these BCTs were coded within each TDF domain (see table 3).

BCTs that occurred frequently across domains included 'Instruction on how to perform the behaviour' (information on current guidelines and knowledge of patient self-management), 'self monitoring of behaviour' (highlighting own prescribing behaviour), 'feedback on behaviour' (the use of audit to scrutinise prescribing practice), social comparison (comparison of behaviour to peers), 'information about health consequences' (consequences of AMR), 'demonstration of behaviour' (physical examination skills and no antibiotic prescribing behaviour), 'problem solving' (patient engagement in decision making) and 'goal setting' (reduce prescribing rate). These are therefore prime BCTs to use for future intervention.

\section{DISCUSSION}

\section{Statement of principal findings}

To our knowledge, this is the first study to use a theoretical framework to identify the factors that influence the antibiotic prescribing behaviour for RTIs, by nurse and pharmacist prescribers, and examine how this might inform the development of an intervention to support appropriate prescribing behaviour. Twelve TDF domains were found to influence the management of RTIs by
Table 3 TDF domains and associated BCTs

BCTs suggested by nurse and pharmacist

Domain prescribers to support behaviour.

\begin{tabular}{|c|c|}
\hline Knowledge & $\begin{array}{l}\text { Instruction on how to perform the behaviour. } \\
\text { Information about health consequences. } \\
\text { Social comparison.* } \\
\text { Feedback on behaviour.* } \\
\text { Credible source. }\end{array}$ \\
\hline Skills & $\begin{array}{l}\text { Instruction on how to perform a behaviour. } \\
\text { Demonstration of the behaviour. }\end{array}$ \\
\hline $\begin{array}{l}\text { Social/professional } \\
\text { role and identity }\end{array}$ & $\begin{array}{l}\text { Identification of self as role model. } \\
\text { Social comparison. } \\
\text { Instruction on how to perform the behaviour. }\end{array}$ \\
\hline $\begin{array}{l}\text { Beliefs about } \\
\text { capabilities }\end{array}$ & $\begin{array}{l}\text { Focus on past success.* } \\
\text { Verbal persuasion about capability. } \\
\text { Mental rehearsal of successful performance. }\end{array}$ \\
\hline $\begin{array}{l}\text { Beliefs about } \\
\text { consequences }\end{array}$ & $\begin{array}{l}\text { Instruction on how to perform the behaviour. } \\
\text { Information about health consequences. } \\
\text { Information about social and environmental } \\
\text { consequences.* } \\
\text { Demonstration of the behaviour. }\end{array}$ \\
\hline Reinforcement & $\begin{array}{l}\text { Material reward (behaviour). } \\
\text { Monitoring behaviour by others without } \\
\text { feedback. } \\
\text { Feedback on behaviour. }\end{array}$ \\
\hline Goals & $\begin{array}{l}\text { Self-monitoring of behaviour. } \\
\text { Goal setting (behaviour). } \\
\text { Review behaviour goal(s). }\end{array}$ \\
\hline $\begin{array}{l}\text { Memory, attention } \\
\text { and decision }\end{array}$ & $\begin{array}{l}\text { Problem solving. } \\
\text { Instruction on how to perform the behaviour. }\end{array}$ \\
\hline
\end{tabular}

processes

\begin{tabular}{|c|c|}
\hline $\begin{array}{l}\text { Environmental } \\
\text { context and } \\
\text { resources }\end{array}$ & $\begin{array}{l}\text { Instruction on how to perform the behaviour. } \\
\text { Prompts and cues. }{ }^{*} \\
\text { Problem solving. }\end{array}$ \\
\hline Social influences & $\begin{array}{l}\text { Social support (unspecified).* } \\
\text { Problem solving. } \\
\text { Social comparison. } \\
\text { Restructuring the social environment. } \\
\text { Goal setting (behaviour). } \\
\text { Information about health consequences. }\end{array}$ \\
\hline Emotion & $\begin{array}{l}\text { Reduce negative emotions. } \\
\text { Information about emotional consequences. } \\
\text { Monitoring of emotional consequences. }\end{array}$ \\
\hline $\begin{array}{l}\text { Behavioural } \\
\text { regulation }\end{array}$ & $\begin{array}{l}\text { Self-monitoring of behaviour.* } \\
\text { Feedback on behaviour. } \\
\text { Social comparison. }\end{array}$ \\
\hline
\end{tabular}

*BCT and associated TDF domains also identified by Cane et al. ${ }^{48}$ BCTs, behaviour change techniques; TDF, Theoretical Domains Framework.

these prescribers based on initial inductive analysis, and 40 naturally occurring BCTs were identified to facilitate the behaviour.

\section{Strengths and weaknesses}

By using the TDF and the BCTTv1, we have identified core ingredients that can be used in interventions to support appropriate antibiotic prescribing by NMPs. A further key strength is that participants were a national sample. However, few were pharmacists, and most worked in general practice. The findings may therefore 
represent the views of nurses working in general practice. However, this picture reflects UK primary care where most prescribers are nurses ${ }^{24}$ with high numbers working in general practice. ${ }^{34}$

Interviews were undertaken iteratively, with no new data relevant to the topic of interest generated in the latter interviews, suggesting data saturation. We did not use random sampling. Participants were an opportunistic sample and therefore may have been more motivated towards appropriate antibiotic prescribing. Less motivated prescribers may have additional deterrents. Hence, the identification of BCTs within the domain of "motivation' may overestimate the occurence of these features in the wider prescribing population.

\section{Comparison with other studies}

Our findings have identified that a broad range of factors influence the prescribing behaviour of nurse and pharmacist prescribers. The limited evidence available has identified some of these influences. Similar to findings reported previously, ${ }^{23}{ }^{37}$ we found that relationships with other prescribers and knowledge of current guidelines influenced behaviour. Diagnostic uncertainty and the clinical condition of the patient, influences we identified, have also been reported. ${ }^{23} 3839$ As in our research, patient expectations for an antibiotic have also been cited. ${ }^{23} 39$ Interestingly, prescribers in our study reported that they saw patient expectations for an antibiotic as an an opportunity to educate patients and that having additional time enabled them to capitablise on this teachable moment. ${ }^{40}$

The TDF has been used to examine the antibiotic prescribing behaviour of doctors working in long-term care facilities ${ }^{41}$ and dental practitioners. ${ }^{42}$ Studies have also explored GPs' adherence to high-impact indicators including avoidance of risky prescribing, ${ }^{43} \mathrm{GP}$ prescribing for older patients in primary care ${ }^{44}$ and inappropriate prescribing by hospital doctors. ${ }^{45}$ As in our research, a broad range of determinants were identified by each study. However, we are unaware of any research that has used the TDF to explore GPs antibiotic prescribing behaviour. Influencing factors identified by studies that are available can broadly be categorised into five domains including social influences (patient expectations ${ }^{12}$ and pressure for an antibiotic ${ }^{13} 46$ ), beliefs about consequences (diagnostic complexity, ${ }^{47}$ prognostic uncertainty ${ }^{14}$ and fear of complications ${ }^{14}$ ), knowledge (lack of consistent treatment guidelines ${ }^{15}$ ), beliefs about capability (self-belief in decision making ${ }^{15}$ ) and environmental context and resources (time pressures ${ }^{15}$ ). Although these factors also influenced NMPs prescribing decisions, a further seven domains in the TDF (skills, social professional role and identity, reinforcement, goals, memory, attention and decision making, emotion and behaviour regulation) unique to NMPs were identified as important determinants of behaviour. Furthermore, within these domains, NMPs used various strategies to overcome perceived barriers to inappropriate prescribing.
Our findings are in-line with expert consensus work ${ }^{48}$ that has mapped BCTs to TDF domains for which they are most likely to be effective. Nine of the BCTs we identified were associated with 7 TDF domains and this supports the associations described by Cane et $a t^{43}$ (see table 3). Furthermore, a review of interventions, designed to increase public antimicrobial awareness and/or to improve AMS, ${ }^{49}$ identified, as in our research, commonly used individual BCTs associated with the TDF domain. Knowledge were 'Information about health consequences' and 'Instruction on how to perform a behaviour'. 'Prompts and cues' were similarly associated with the domain 'Environmental Context and Resources'. 'Monitoring of behaviour without feedback' and 'Feedback on behaviour', also BCTs identified as important in our research, were reported by these researchers to be unique to the most successful interventions.

\section{Meaning of the study: possible explanations and implications for clinicians and policy makers}

Our findings can be used as the basis for development of a theoretically informed intervention to support appropriate prescribing by nurse and pharmacist prescribers. They can also be used by practitioners to identify their individual facilitators and barriers to appropriate prescribing. Numerous intervention are available that target the antibiotic prescribing behaviour of GPs. Although these interventions could potentially target some of the drivers of behaviour among NMPs, they are unlikely to target all of these drivers. Future interventions should target the seven domains unique to NMPs that this study has identified.

\section{Unanswered questions and future research}

The next step is to develop an intervention based on our findings and test its feasibility and acceptability among nurse and pharmacist prescribers and whether it results in lasting changes to antibiotic prescribing behaviours.

\section{CONCLUSION}

Given that increasing numbers of NMPs working in primary care and managing infections, it is important that these findings are used to inform theoretically grounded interventions to support appropriate prescribing behaviour by these groups.

\section{Author affiliations}

${ }^{1}$ Healthcare Sciences, Cardiff University, Cardiff, UK

${ }^{2}$ Menzies Centre for Health Policy, University of Sydney, Sydney, New South Wales, Australia

${ }^{3}$ School of Pharmacy, Reading University, Reading, UK

${ }^{4}$ Health Sciences, University of Manchester, Manchester, UK

${ }^{5}$ Londonwide LMC, Londonwode LMCs and Londonwide Enterprise Ltd, London, UK, UK

${ }^{6}$ Department of Sport Science and Physical, University of Bedfordshire, Luton, UK

Acknowledgements We would like to thank Tom Courtenay for his assistance with data collection and analysis. We would also like to thank the RCN General Practice Nurse Forum, the Royal Pharmaceutical Society (RPS) Pharmacist Prescribing Discussion Group (783 members), Prescribing and Medicines Management Group 
(520 members) and Pharmacist Working in GP practice Discussion Group (531 members) and the Queens Nurse Network (QNI) (1200 members) for their help with recruitment. We would also like to thank the nurse and pharmacist prescribers who participated in this research. Without their participation, this work would not have been possible.

Contributors $\mathrm{MC}$ made a substantial contribution to the conception and design of the work; the acquisition and interpretation of data; and drafting of the work. SR and $\mathrm{AC}$ made a substantial contribution to the design of the work, the acquisition, analysis and interpretation of data and drafting of the work. RL, SP and KY made a substantial contribution to the acquisition and interpretation of data and critically revised drafts of the work. All authors approved the final version to be published and agree to be accountable for all aspects of the work in ensuring that questions related to the accuracy or integrity of any part of the work are appropriately investigated and resolved.

Funding This research was funded by an industrial grant.

Disclaimer All authors had full access to all the data in the study and can take responsibility for the integrity of the data and the accuracy of the data analysis.

Competing interests None declared.

Patient consent for publication Not required.

Ethics approval Ethical approval was provided by the School of Healthcare Sciences Research Governance and Ethics Committee, Cardiff University (4475REC).

Provenance and peer review Not commissioned; externally peer reviewed.

Data sharing statement No additional data available; that is, the dataset supporting the conclusions of this article is included within the article.

Open access This is an open access article distributed in accordance with the Creative Commons Attribution Non Commercial (CC BY-NC 4.0) license, which permits others to distribute, remix, adapt, build upon this work non-commercially, and license their derivative works on different terms, provided the original work is properly cited, appropriate credit is given, any changes made indicated, and the use is non-commercial. See: http://creativecommons.org/licenses/by-nc/4.0/.

\section{REFERENCES}

1. WHO. Antimicrobial resistance fact sheet no. 194. 2017 http://www. who.int/mediacentre/factsheets/antibiotic-resistance/en/

2. European Commission - Fact Sheet. New EU action plan on antimicrobial resistance - questions and answers. Brussels, 2017.

3. Van Boeckel TP, Gandra S, Ashok A, et al. Global antibiotic consumption 2000 to 2010: an analysis of national pharmaceutical sales data. Lancet Infect Dis 2014;14:742-50.

4. Holmes AH, Moore LS, Sundsfjord A, et al. Understanding the mechanisms and drivers of antimicrobial resistance. Lancet 2016;387:176-87.

5. Costelloe C, Metcalfe C, Lovering A, et al. Effect of antibiotic prescribing in primary care on antimicrobial resistance in individual patients: systematic review and meta-analysis. BMJ 2010;340:c2096.

6. O'Neill J. Review on antimicrobial resistance: Tackling a crisis for the health and wealth of nations. https://amr-review.org/sites/default/ files/AMR\%20Review\%20Paper\%20\%20Tackling\%20a\%20crisis\% 20 for\%20the $\% 20$ health $\% 20$ and $\% 20$ wealth\%20 of\%20nations_1.pdf

7. Goossens H, Ferech M, Vander Stichele R, et al. Outpatient antibiotic use in Europe and association with resistance: a cross-national database study. Lancet 2005;365:579-87.

8. Gulliford MC, van Staa T, Dregan A, et al. Electronic health records for intervention research: a cluster randomized trial to reduce antibiotic prescribing in primary care (eCRT study). Ann Fam Med 2014;12:344-51.

9. Shapiro DJ, Hicks LA, Pavia AT, et al. Antibiotic prescribing for adults in ambulatory care in the USA, 2007-09. J Antimicrob Chemother 2014;69:234-40.

10. WHO. Antimicrobial resistance Fact sheet No. 194. 2016 http://www. who.int/mediacentre/factsheets/fs194/en/World

11. Glasziou PP, Del Mar CB, Sanders SL, et al. Antibiotics for acute otitis media in children. Cochrane Database Syst Rev 2004:CD000219.

12. Tonkin-Crine S, Yardley L, Little P. Antibiotic prescribing for acute respiratory tract infections in primary care: a systematic review and meta-ethnography. J Antimicrob Chemother 2011;66:2215-23.

13. Coenen S, Michiels B, Renard D, et al. Antibiotic prescribing for acute cough: the effect of perceived patient demand. Br J Gen Pract 2006;56:183-90.
14. Kumar S. Why do general practitioners prescribe antibiotics for sore throat? Grounded theory interview study. BMJ 2003;326:138.

15. Brookes-Howell L, Hood K, Cooper L, et al. Understanding variation in primary medical care: a nine-country qualitative study of clinicians' accounts of the non-clinical factors that shape antibiotic prescribing decisions for lower respiratory tract infection. BMJ Open 2012;2:e000796.

16. Ranji S, Steinman M, Shojania K, et al. Interventions to reduce unnecessary antibiotic prescribing: a systematic review and quantitative analysis medical care. 2008;46:847-62.

17. Arnold SR, Straus SE. Interventions to improve antibiotic prescribing practices in ambulatory care. Cochrane Database Syst Rev 2005:CD003539ARR.

18. Coxeter P, Del Mar CB, McGregor L, et al. Interventions to facilitate shared decision making to address antibiotic use for acute respiratory infections in primary care. Cochrane Database Syst Rev 2015:CD010907.

19. Courtenay M, Gillespie D, Lim R. Patterns of dispensed nonmedical prescriber prescriptions for antibiotics in primary care across England: a retrospective analysis. J Antimicrob Chemother 2017;72:2915-20.

20. NHS England. NHS five year forward view. $2014 \mathrm{https} / / / \mathrm{www}$ england.nhs.uk/ ourwork/futurenhs/

21. DoH. Operational productivity and performance in English NHS acute hospitals. London: DoH, 2016.

22. Health Education England. Primary care workforce commission. 2016 https://hee.nhs.uk/our-work/hospitals-primary-community-care/ primary-community-care/primary-care-workforce-commission

23. Rowbotham S, Chisholm A, Moschogianis S, et al. Challenges to nurse prescribers of a no-antibiotic prescribing strategy for managing self-limiting respiratory tract infections. J Adv Nurs 2012;68:2622-32.

24. Courtenay M, Rowbotham S, Lim R, et al. Antibiotics for acute respiratory tract infections: a mixed-methods study of patient experiences of non-medical prescriber management. BMJ Open 2017;7:e013515.

25. Germeni E, Frost J, Garside R, et al. Antibiotic prescribing for acute respiratory tract infections in primary care: an updated and expanded meta-ethnography. Br J Gen Pract 2018;68:e633-e645.

26. Michie S, van Stralen MM, West R. The behaviour change wheel: a new method for characterising and designing behaviour change interventions. Implement Sci 2011;6:42.

27. Courtenay M, Lim R, Castro-Sanchez E, et al. Development of consensus-based national antimicrobial stewardship competencies for UK undergraduate healthcare professional education. J Hosp Infect 2018;100:245-56.

28. McCullough AR, Glasziou PP. Delayed antibiotic prescribing strategies--time to implement? JAMA Intern Med 2016;176:29-30.

29. Michie S, Atkins L, West R. The behaviour change wheel: a guide to designing interventions. 2014 www.behaviourchangewheel.Com

30. Cane J, O'Connor D, Michie S. Validation of the theoretical domains framework for use in behaviour change and implementation research. Implement Sci 2012;7:37.

31. Craig P, Dieppe P, Macintyre S, et al. Developing and evaluating complex interventions: the new Medical Research Council guidance. BMJ 2008;337:a1655

32. Michie S, Richardson M, Johnston M, et al. The behavior change technique taxonomy (v1) of 93 hierarchically clustered techniques: building an international consensus for the reporting of behavior change interventions. Ann Behav Med 2013;46:81-95.

33. Courtenay M, Khanfer R, Harries-Huntly G, et al. Overview of the uptake and implementation of non-medical prescribing in Wales: a national survey. BMJ Open 2017;7:e015313.

34. Latter S, Blenkinsopp A, Smith A, et al. Evaluation of nurse and pharmacist independent prescribing: University of Southampton and University of Keele on behalf of the DoH, 2010.

35. Braun V, Clarke V. Using thematic analysis in psychology. Qual Res Psychol 2006;3:77-101.

36. Alexander KE, Brijnath B, Mazza D. Barriers and enablers to delivery of the Healthy Kids Check: an analysis informed by the Theoretical Domains Framework and COM-B model. Implement Sci 2014;9:60.

37. Williams SJ, Halss AV, Moore MV, et al. General practitioner and nurse prescriber experiences of prescribing antibiotics for respiratory tract infections in UK primary care out-of-hours services (the UNITE study). Journal of Antimicrobial Chemotherapy 2017

38. Abbo L, Smith L, Pereyra M, et al. Nurse practitioners' attitudes, perceptions, and knowledge about antimicrobial stewardship. The Journal for Nurse Practitioners 2012;8:370-6.

39. Adorka M, Dikokole M, Mitonga KH, et al. Healthcare providers attitudes and perceptions in infection diagnosis and antibiotic prescribing in public health institutions in Lesotho: a cross sectional survey. Afr Health Sci 2013;13:344-50. 
40. Lawson PJ, Flocke SA. Teachable moments for health behavior change: a concept analysis. Patient Educ Couns 2009;76:25-30.

41. Fleming A, Bradley C, Cullinan S, et al. Antibiotic prescribing in longterm care facilities: a qualitative, multidisciplinary investigation. $B M J$ Open 2014;4:e006442.

42. Newlands R, Duncan EM, Prior M, et al. Translation Research in a Dental Setting (TRiaDS) Research Methodology Group. Barriers and facilitators of evidence-based management of patients with bacterial infections among general dental practitioners: a theory-informed interview study. Implement Sci 2016;11:11.

43. Lawton R, Heyhoe J, Louch G, et al. Using the Theoretical Domains Framework (TDF) to understand adherence to multiple evidencebased indicators in primary care: a qualitative study. Implement Sci 2016;11:113.

44. Riordan DO, Byrne S, Fleming A, et al. GPs' perspectives on prescribing for older people in primary care: a qualitative study. $\mathrm{Br} \mathrm{J}$ Clin Pharmacol 2017;83:1521-31.
45. Cullinan S, Fleming A, O'Mahony D, et al. Doctors' perspectives on the barriers to appropriate prescribing in older hospitalized patients: a qualitative study. Br J Clin Pharmacol 2015;79:860-9.

46. Lucas PJ, Cabral C, Hay AD, et al. A systematic review of parent and clinician views and perceptions that influence prescribing decisions in relation to acute childhood infections in primary care. Scand $J$ Prim Health Care 2015;33:11-20.

47. Whaley LE, Businger AC, Dempsey PP, et al. Visit complexity, diagnostic uncertainty, and antibiotic prescribing for acute cough in primary care: a retrospective study. BMC Fam Pract 2013;14:120.

48. Cane J, Richardson M, Johnston M, et al. From lists of behaviour change techniques (BCTs) to structured hierarchies: comparison of two methods of developing a hierarchy of BCTs. Br J Health Psychol 2015;20:130-50.

49. McParland JL, Williams L, Gozdzielewska L, et al. What are the 'active ingredients' of interventions targeting the public's engagement with antimicrobial resistance and how might they work? Br J Health Psychol 2018;23:804-19. 
Correction: Examining influences on antibiotic prescribing by nurse and pharmacist prescribers: a qualitative study using the Theoretical Domains Framework and COM-B

Courtenay M, Rowbotham S, Lim R, et al. Examining influences on antibiotic prescribing by nurse and pharmacist prescribers: a qualitative study using the Theoretical Domains Framework and COM-B. BMJOpen 2019;9:e029177. doi: 10.1136/bmjopen-2019-029177

This article was previously published with errors in data and author affiliation.

- The correct author affiliations for Angel Chater are

School of Sport Science and Physical Activity, University of Bedfordshire, Bedford, UK.

University College London School of Pharmacy, London, UK.

- In the 'Introduction' section, fourth paragraph, the data should be '34 000 nurses and 8000 pharmacists' instead of '30 000 nurses and 4000 pharmacists'.

- The correct casing for 'Intervention Functions' is Intervention Functions throughout the article.

- The abbreviation for nurse in '( $\mathrm{I}=$ interviewee, $\mathrm{n}=$ nurse, $\mathrm{P}=$ pharmacist $)$ ' is $\mathbf{N}$ under 'Factors influencing the management of RTIs' subsection in 'Results'.

- Under the section 'Factors influencing the management of RTIs', the correct sub-heading is 'Goals (reflective motivation)' instead of 'Goals (automatic motivation)'.

- Under 'Comparison with other studies' in 'Discussion', the period should be removed before the word 'knowledge'. The correct statement is '... associated with the TDF domain knowledge, were 'Information about...'.

- In Supplementary Table 1, the Theoretical Domain 'Goals' is part of Motivation (Reflective) column instead of Motivation (Automatic). Motivation (Automatic) begins from 'Reinforcement'.

Open access This is an open access article distributed in accordance with the Creative Commons Attribution Non Commercial (CC BY-NC 4.0) license, which permits others to distribute, remix, adapt, build upon this work non-commercially, and license their derivative works on different terms, provided the original work is properly cited, appropriate credit is given, any changes made indicated, and the use is non-commercial. See: http://creativecommons.org/licenses/by-nc/4.0/.

(c) Author(s) (or their employer(s)) 2019. Re-use permitted under CC BY-NC. No commercial re-use. See rights and permissions. Published by BMJ.

BMJ Open 2019;9:e029177corr1. doi:10.1136/bmjopen-2019-029177corr1

Check for updates 